\title{
Shale Gas Exploration Potential in Southwestern Shandong Province of Eastern China
}

\author{
Li Cuifang *, Huang Xinglong, Shao Yubao and Dou Fengke \\ Shandong Institute of Coal Geology Planning and Exploration, Jinan, China
}

The shale layers of the Permian Shanxi Formation and Taiyuan Formation in the southwestern part of Shandong Province are marine-continental transitional sedimentary facies. When compared with the Ordos Basin, which was a typical breakthrough in marine-continental transitional shale gas exploration, the geological

OPEN ACCESS

Edited by:

Dawei LV,

Shandong University of Science and

Technology, China

Reviewed by:

Peng Li,

SINOPEC Petroleum Exploration and

Production Research Institute, China

Ziqi Feng,

China University of Petroleum (East

China), China

${ }^{*}$ Correspondence:

Li Cuifang

76901802@qq.com

Specialty section:

This article was submitted to

Sedimentology, Stratigraphy and

Diagenesis,

a section of the journal

Frontiers in Earth Science

Received: 30 April 2021

Accepted: 23 July 2021

Published: 26 August 2021

Citation:

Cuifang $L$, Xinglong $H$, Yubao $S$ and Fengke D (2021) Shale Gas Exploration Potential in Southwestern Shandong

Province of Eastern China.

Front. Earth Sci. 9:702902.

doi: 10.3389/feart.2021.702902 characteristics, exploration, and development prospects of marine-continental transitional shale gas in the southwestern section of Shandong Province are more defined. The shale gas deposits of the Shanxi and Taiyuan Formations in southwestern Shandong Province have the following geological characteristics. The sedimentary environments of Shanxi and Taiyuan Formations are considered to be stable and characterized with widely distributed organic-rich shale, which can be used as composite evaluation layers. The total thickness of the shale range is between 140 and $350 \mathrm{~m}$, with an average of $230 \mathrm{~m}$. The main types of organic matter in the Shanxi Formation are Type III and Type $\mathrm{II}_{2}$ kerogen, while the main types of organic matter in the Taiyuan Formation are rock types. The abundance and maturity of the organic matter are high, and the gas generating capacity is strong. The reservoir rock mineral composition is complex in the region. The clay mineral content is relatively high and the brittle mineral content is rich. Also, the shale fracturing ability is good. The region has the characteristics of a low porosity and low permeability reservoir, with relatively good reservoir capacity. Three primary points of interest have stably been developed within the region, which are located in the upper high water level system, near the initial flood surface, and the majority of flood surface, including a transgressive system tract and high level system tract. The total gas content is estimated to range between 0.03 and $4.47 \mathrm{~m}^{3} / \mathrm{t}$, with an average of $0.30 \mathrm{~m}^{3} / \mathrm{t}$. The shale gas resources are rich, including one favorable Class I location with an area of $819.06 \mathrm{~km}^{2}$ and a resource amount of $985.84 \times 108 \mathrm{~m}^{3}$; four favorable Class II locations with an area of $1,979.68 \mathrm{~km}^{2}$ and a resource amount of 2,278.14 $\times 108 \mathrm{~m}^{3}$; and five prospective locations with an area of $8,385.52 \mathrm{~km}^{2}$ and a resource amount of $7,299.48 \times$ $10^{8} \mathrm{~m}^{3}$. Therefore, the region was considered to have major exploration potential.

Keywords: Shanxi formation-Taiyuan formation composite evaluation layer, shale gas, mud shale, exploration potential, Type III, total organic carbon content 


\section{INTRODUCTION}

Outside of North America, China is currently the largest shale gas producer in the world. It is expected that with the continuing breakthroughs which are being made in domestic shale gas exploration and development, the development potential and prospects of shale gas will attract significant attention from researchers (Zou et al., 2021). Shale gas is a type of unconventional natural gas which exists mainly in either an adsorbed or free state. Shale gas is self-generating and selfstoring and continually accumulates in shale deposits. Adsorbed gas occurs on the surfaces of organic matter or clay minerals, and free gas occurs in matrix pores and cracks (Zhang et al., 2004; Zou et al., 2010). Therefore, shale gas reservoirs' storage and fluid permeability characteristics are highly valued.

In recent years, in the region of the Ordos Basin Permian Taiyuan-Shanxi Group; Qinshui Basin of the Hunan Permian Dalong-Longtan Group; and the Permian Longtan Group of the eastern Sichuan Basin, well-drilling test results have revealed a sea-land transition phase of shale gas exploration and development potential. The Ordos Basin, which is a transitional facies shale gas resource, is one of the main exploration sites. The single well of the Shanxi Formation has attained stable gas production, highly controlled reserves, and good formation recoverability and fracturing ability. It is expected that a breakthrough will soon be made in the eastern margin of the basin and large-scaled production will be achieved (Kuang et al., 2020). According to the national shale gas survey and evaluation carried out by the Ministry of Land and Resources in 2012, it is believed that massive thick shale gas reservoirs have developed in the Carboniferous Permian of the southern section of northern China and other North China regions (2012). It has been found that although the shallow areas of Shandong Province lack oil and gas resources, the deeper areas have become research hotspots for the exploration of unconventional oil and gas resources. The Late Paleozoic mixed marine-terrestrial deposits in the North China region are rich in mud shale. There are relatively high degrees of evolution not only the shale-rich Carboniferous Permian shale preserved intact but the source rock in the coal measures in the deep areas of western Shandong. These findings have resulted in the deeper areas of western Shandong becoming the focus of shale gas research in recent years. Zhang et al. (2012a) comprehensively evaluated the shale occurrence layers, gas generation potential, and development feasibility and proposed that the areas with the highest potential for shale gas in Shandong Province include the Jiyang Concavity, Linqing Concavity, Jiaolai Concavity, Huang County Depression, and the southwestern Shandong buried uplift area. Zhang et al. (2019) believed that the Type II and III Kerogen of the Shanxi-Taiyuan Formation mixed marine-terrestrial shale, as well as the Type II and III Cenozoic Kong 2 lacustrine shale and the Type I and II lacustrine shale between the Cenozoic Sha 4 and Sha 3 strata of the Shahejie Formation, were also favorable exploration strata for shale gas in Shandong. It has been estimated to be $1.42 \times 1012 \mathrm{~m}^{3}$ of the resource present in Shandong's favorable shale gas exploration areas. Han et al. (2015) proposed that the Taiyuan Formation in western
Shandong has excellent shale gas potential due to its characteristics of high thickness; moderate burial depths; high organic matter content levels; Types II and III kerogen; high gas adsorption capacity; high maturity; high brittle mineral content; and well-developed pores and fissures. Wang (2016) believed that the dark shale of the Shanxi-Taiyuan and Heishan Formations in western Shandong has favorable conditions for shale gas formation and predicted the Cao County Coalfield, Yutai Depression, Huanghebei Coalfield, and Yanggu-Chiping Coalfield as four prospective areas. Gong et al. (2018) considered that the Upper Paleozoic dark shale in western Shandong had high thickness; high abundance of organic matter (primarily Type III); moderate thermal evolution; welldeveloped micropores and nanopores; high brittle mineral content; and good sealing conditions, making it conducive to shale gas accumulation. Huang (2018) and Li (2020a) (Li, 2020b) pointed out that the shale of the Shanxi-Taiyuan Formation in the coal-bearing area of southwestern Shandong is part of the lowporosity and low-permeability reservoirs of the region, which are known to have high brittle mineral content and high organic matter abundance, as well as both low-maturity strata and mature strata. The Jining Depression was the area with the highest hydrocarbon generation potential.

The above-mentioned studies indicated that as a potential shale gas area, the southwestern section of Shandong Province is characterized by the complete development of Carboniferous and Permian systems and organic-rich shale. However, there remains a lack of understanding of the distribution patterns of favorable intervals, and the prospects of exploration and development have yet to be clarified. These factors have restricted large-scaled development projects in the region. It was assumed in this study that by systematically combing the geological characteristics of marine-continental transitional shale gas in the Shanxi and Taiyuan Formations in the southwestern Shandong Province and then comparing the findings with the typical marine-continental transitional shale gas characteristics of the Ordos Basin, the geological conditions and exploration and development prospects of the shale gas in the Shanxi and Taiyuan Formations could be successfully clarified. The goal of this study was to clearly point out the most effective directions for the pursuit of unconventional oil and gas explorations in western Shandong Province.

\section{GEOLOGICAL BACKGROUND}

The study area was located within the eastern portion of the North China Plate (Level I structural unit). The study area was a buried uplift area of the southwestern Shandong Uplift (Zhang et al., 2014), which could be further divided into the HezeYanzhou Buried Uplift Level IV structural unit, and thirteen Level 5 structural units (Heze Buried Bulge, Chengwu Buried Depression, Wenshang-Ningyang Buried Depression, Jiaxing Buried Bulge, Jining Buried Depression, Yanzhou Buried Bulge, Jinxiang Buried Depression, Shilou Buried Depression, Qingkuji Buried Bulge, Huanggang Buried Depression, Longwangmiao Buried Bulge, Yutai Depression, and Tengzhou 
Buried Depression). There were observed to be many geotectonic units across the study area, with obvious differences in the structural characteristics and structural evolutions found among the various structural units. These differences made the overall structural characteristics of the region more complex. In the study area, brittle fractures were determined to be the primary structural deformations. These deformations had occurred since the Mesozoic Period and were widely developed.

The regional stratigraphy was determined to fall under the western Shandong stratigraphic division of the Hebei-ShandongHenan (Jin-Ji-Lu-Yu) stratigraphic area within the North China stratigraphic region (Zhang et al., 2014). The generational strata in each section of the study area were observed to be relatively complete, ranging from the Neoarchean to the Quaternary. Among those, the Taiyuan Carboniferous Formation and the Shanxi Permian Formation were the target intervals for this study's shale gas survey in western Shandong. The stratum thickness, lithology, and number of coal seams of the Shanxi Formation varied by location. However, thicknesses tended to decrease from NE to SW. In terms of lithology, the proportion of sandstone in Jining and Zaozhuang is known to be high and becomes thicker and coarser from SW to NE. There were obvious differences observed between the coal seams located in the northern and southern sections. For example, proceeding north from the Ningwen area, there were found to be relatively more coal seams. However, they were thinner, with generally only two layers of coal which could be potentially mined. The Jining-Linyi area generally contained two to three layers of coal, with each single layer being relatively thick and stable. Changes in the coal seams occurred horizontally, making them primary coal mining seams and highly valuable for industrial use.

\section{EXPERIMENTAL TESTING EQUIPMENT AND DATA ACQUISITION}

This study's sample testing content included the shale organic geochemical characteristics (kerogen microscopic composition, organic carbon content, rock pyrolysis, and vitrinite reflectance); reservoir characteristics (mineral composition, porosity, and permeability); and the gas-bearing characteristics (on-site desorption and gas composition analysis results). The kerogen microscopic compositions (SY/T 5125-2014) and vitrinite reflectance (SY/T 5124-2012) were measured using an Axio Scope.A1 microphotometer. The organic carbon content levels (GB/T19145-2003) were measured using a US LECO-CS230 carbon and sulfur analyzer. The rock pyrolysis (GB/T 18602-2012) was conducted using a ROCK-EVAL VI rock pyrolysis analyzer (France). The X-ray diffraction analyses of the clay minerals and common nonclay minerals in the sedimentary rocks (SY/T 5163-2010) were conducted using a Dutch PANalytial brand X'Pert Pro X-ray diffractometer. A Poro PDP-200 overburden porosity and permeability measuring instrument was used to measure the porosity and permeability (SY/T 6385-1999) of the samples. The shale gas content levels (GB/T 19559-2008) were determined using a SH-CBM8 fully automatic high-precision coalbed methane/shale gas content multichannel detector and HT-4 residual gas detector Hengtai Shanghe Energy Technology (Beijing) Co., Ltd. Finally, this study's gas composition analysis (GB/T 13610-2014) was conducted using an Agilent 7,890 gas chromatograph.

\section{CHARACTERISTICS OF THE SHALE BASE SOURCE ROCK}

\section{Sedimentary Environmental and Distributions}

Sedimentary environmental conditions play key roles in the formation of organic-rich mud shale (Zou et al., 2014; Lv et al., 2019; Lv et al., 2020). The Carboniferous-Permian shale in southwestern Shandong is known to have evolved from the surface sea deposits in cratonic basins to offshore river-delta-lake deposits (Chen, 2000). In the present research investigation, the field geological profiles, macrosedimentary facies analysis of borehole cores, and the types of lithofacies in the study area were utilized to determine that, based on the vertical combination relationships of the various lithofacies and the characteristics of their distributions across the plane, the Taiyuan Formation and the Shanxi Formation in the southwestern Shandong area were previously a large surface sea basin. The area's sedimentary systems were identified as being primarily tidal flat sedimentary systems, barrier-lagoon sedimentary systems, and large river-dominated shallow-water delta sedimentary systems. During the Early to Late Permian Period, the study area was mainly a set of epicontinental sea barrier coastal sedimentation deposits. The sea water gradually withdrew from north to south, and the climate changed to an arid climate. In addition, the coastal river-deltaic lacustrine sedimentation system transitioned to the west of Shandong, which was a sedimentation sequence of sea level fall and basin progression. In previous laboratory tests, the Heishan Member of the Shihezi Formation was proven to be characterized with low brittle mineral content, TOC, porosity, permeability, and gas content $\left(<0.2 \mathrm{~m}^{3} / \mathrm{t}\right)$, which had been removed from the evaluation layer. The Shanxi Formation and Taiyuan Formation were found to have similar sedimentary environments, stable stratigraphic development, and small effective thicknesses after the limestone was removed, with coal seams and sandstone layers larger than $3 \mathrm{~m}$ observed. The expert group of Provincial Department of Natural Resources confirmed that Shanxi Formation and Taiyuan Formation had been combined as a composite evaluation layer. The extent of Carboniferous-Permian erosion has been observed to vary greatly in each fault block in southwestern Shandong. The effective thicknesses of the shale of the Shanxi and Taiyuan Formations in the study area range between 140 and $350 \mathrm{~m}$, with an average thickness of $230 \mathrm{~m}$. Those thicknesses are greater than that of marine-continental shale located in the Ordos Basin (30-40 $\mathrm{m}$ in Shanxi and 30-60 $\mathrm{m}$ in Taiyuan) (Zhai et al., 2020). The two thickest centers were determined to be the south side of Well CY1 and the west side of Well Beibu2, as detailed in Figure 1. The west side of Well Beibu2 was the thickest at up to $350 \mathrm{~m}$, and the thinnest shale layers were approximately $140 \mathrm{~m}$, which were 


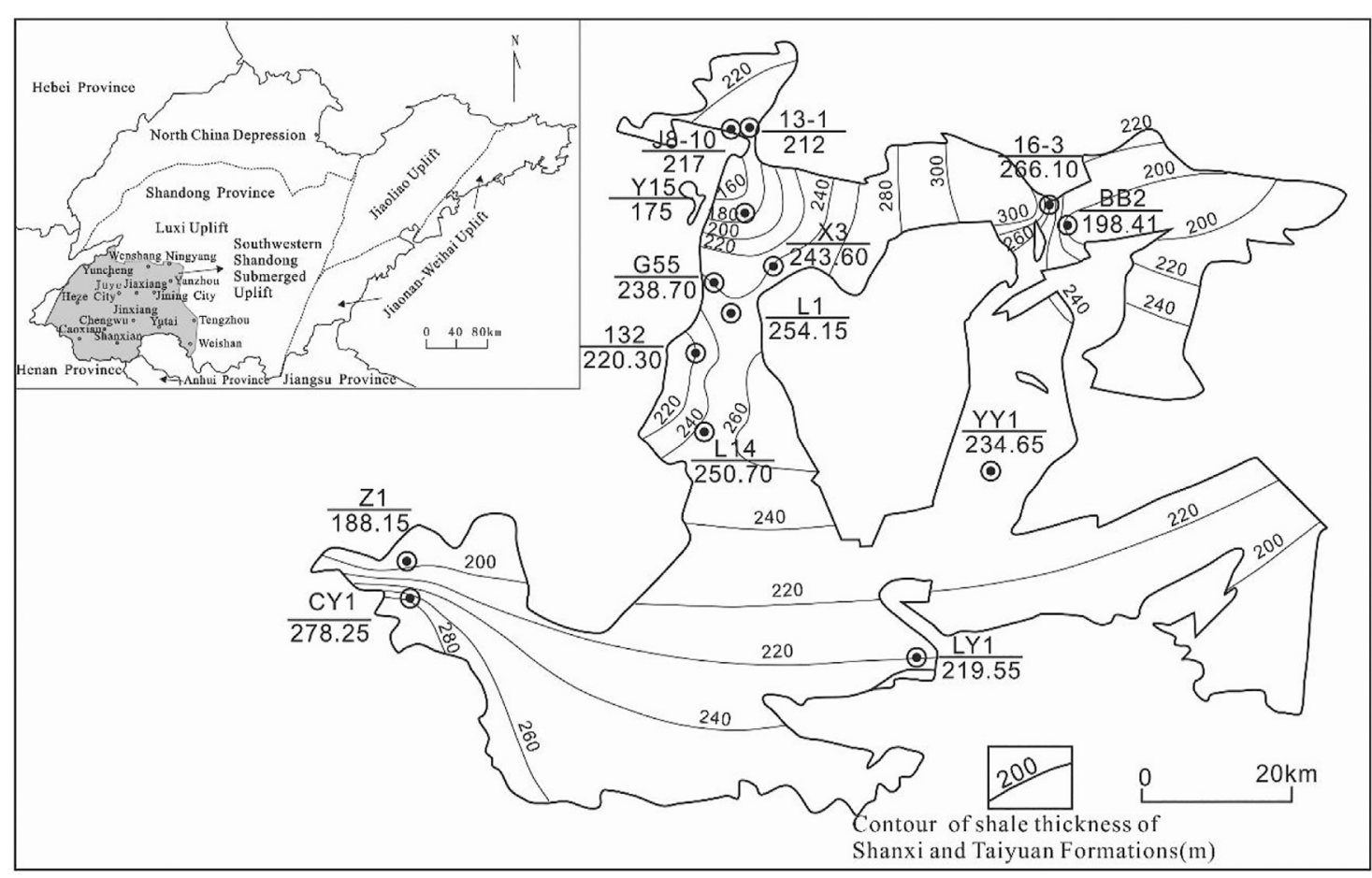

FIGURE 1 | Contour map of the shale thicknesses of Shanxi and Taiyuan Formations.

located on the north side of Well Y15 (175 m). According to the comprehensive analysis of the drilling exposures combined with seismic interpretations, the effective burial depths of the shale in the Shanxi and Taiyuan Formations ranged from 0 to 5,000 $\mathrm{m}$. Those depths were controlled by the structural characteristics and observed to vary greatly.

\section{Characteristics and Evolution of the Sequence Stratigraphy}

According to regional unconformity surfaces and regional tectonic stress transformation surfaces, the Benxi Formation, Taiyuan Formation, and Shanxi Formation in the study area were divided into three third-order sequence structural sequences SIII1-S section 3 and eight fourth-order sequences SIV2-SIV8, as shown in Figure 2. The Benxi Formation corresponded to the transgressive system tract of Sequence SIII1. The Taiyuan Formation corresponded to the high system tract of Sequence $S$ square 1 and the entirety of Sequence $S$ square 2 . The Shanxi Formation corresponded to the entirety of Sequence S square 3. Sequence SIII1 mainly included a developed transgressive system tract and high system tract. The bottom of the sequence was a regional unconformity surface, an interface between Ordovician and Carboniferous. The majority of the oceanic flood surfaces were located at the bottom of the L2 limestone, where coal seams 17 and 18 were developed. Sequence SIII2 mainly included a developed transgressive system tract and high system tract. The bottom boundary of the sequence was mainly a $16_{2}$ coal seam which had formed in a lagoon and swamp environment. The majority of the oceanic flood surfaces were located at the bottom of the L9 limestone. This study observed that Seams 6, 8, 9, 10, $12_{1}, 12_{2}, 14,15_{1}, 15_{2}, 16_{1}$, and $16_{2}$ were all developed. In addition, Sequence SIII3 corresponded to the Shanxi Formation, which included a low-level system tract, transgressive system tract, and high-level system tract. The initial sea flood surfaces were located on the floor of No. 3 coal seam, and the maximum sea flood surfaces were located on No. 2 coal seam or the top of No. 3 coal seam. The sequence bottom interfaces were mainly the cut valley of the distributary channel in the lower delta plain, along with the interfaces of the Shanxi Formation and Taiyuan Component. No. 2 and No. 3 coal seams were developed, among which No. 3 coal seam was thicker and was the main mined coal seam in the area. To explain the evolution of the sedimentary environment in the Carboniferous and Permian coal measure sequence framework of the study area, a comparison map of the three-level sequence sedimentary environment was compiled along the east-west direction. The evolution of the sedimentary environment under the sequence framework is detailed in Figure 3. The sedimentary environment evolved under the sequence framework of the study area. With the decline in the sea level, the basin evolved from the epicontinental sea of the craton basin to the offshore fluvial-deltaic lacustrine deposits. The Carboniferous Benxi Formation mainly developed from the offshore shelf system, followed by the barrier-tidal flat-lagoon systems. The Late Carboniferous to Early Permian Taiyuan Formation mainly developed from the barrier-tidal flat-lagoon 


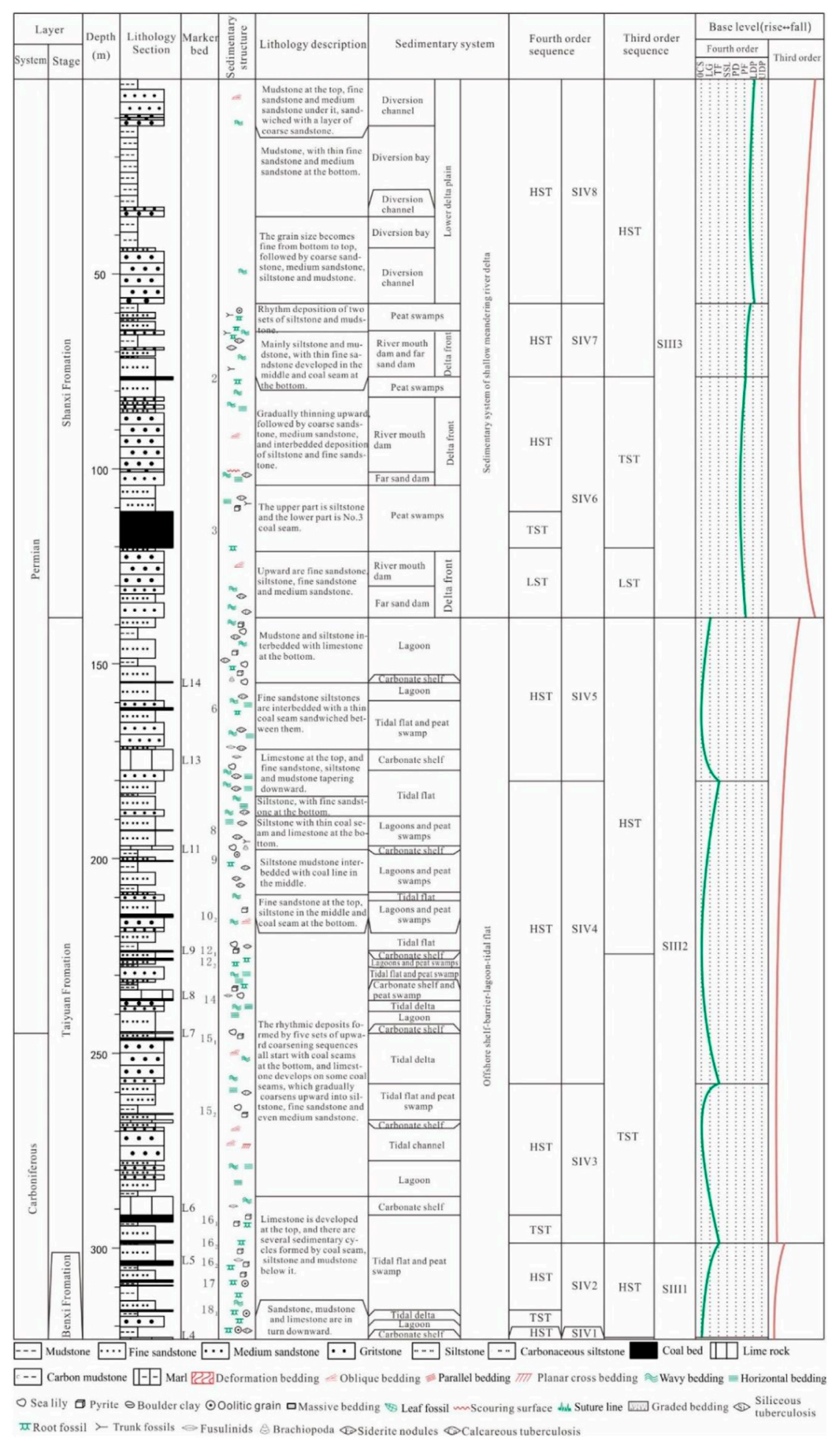

FIGURE 2 | Well XLZ-47: Comprehensive histogram of the sedimentary facies and sequence stratigraphy of the Carboniferous-Permian coal-bearing series.

depositional systems, followed by the offshore shelf depositional system. The lower part of the Shanxi Formation was determined to be mainly composed of a set of shallow water deltaic lower delta plains. Meanwhile, the upper part of the Shanxi Formation was observed to be composed of shallow water deltaic upper delta plains and meandering river deposits. 


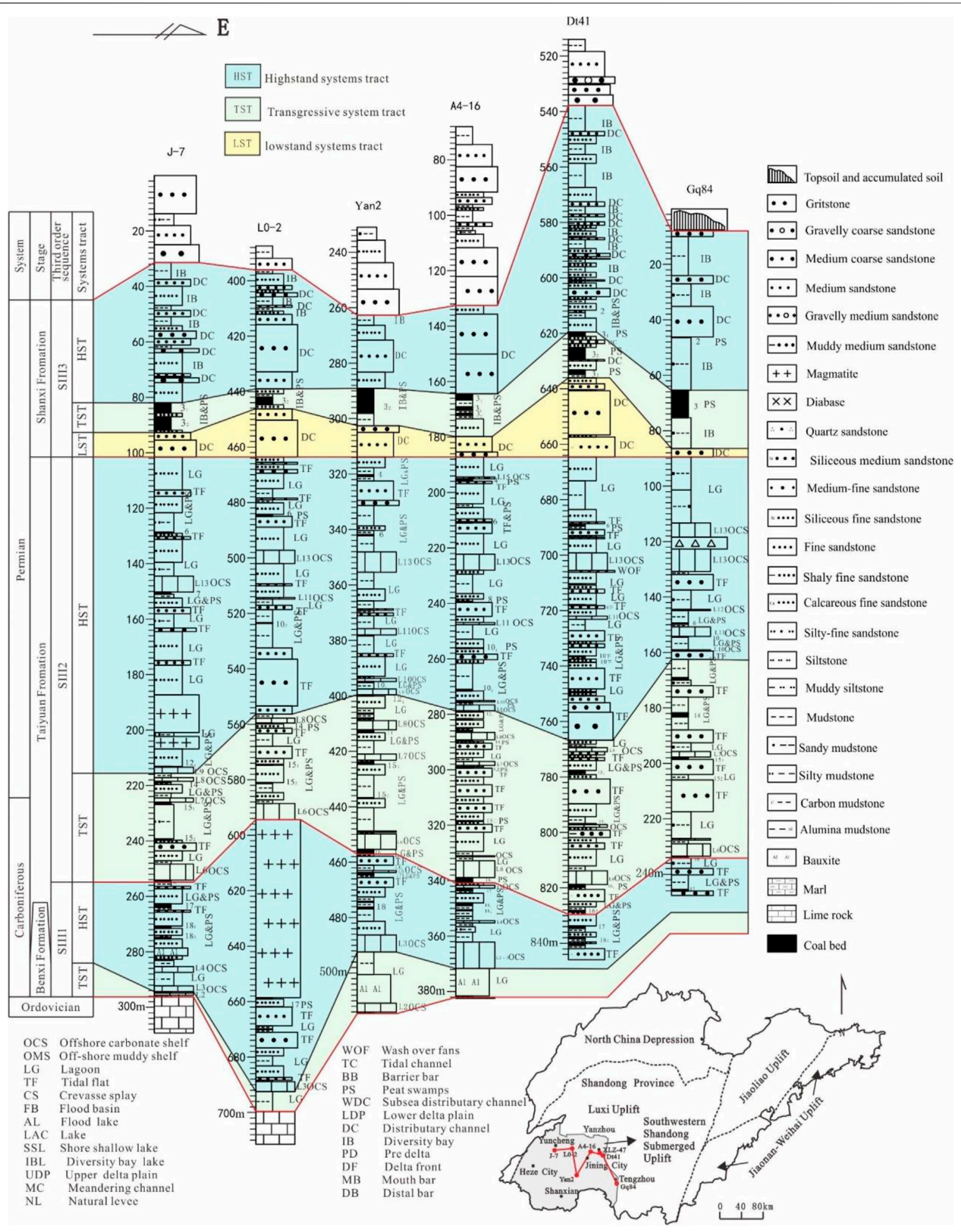

FIGURE 3 | Sedimentary facies and sequence stratigraphic correlation map (West to East). 
TABLE 1 | Evaluation criteria for the abundance of organic matter in coal-measure source rock of sea and land interactions (Chen et al., 1997).

\begin{tabular}{|c|c|c|c|c|c|c|}
\hline \multirow[t]{2}{*}{ Oil source rock type } & \multirow[t]{2}{*}{ Evaluation parameters } & \multicolumn{5}{|c|}{ Source rock grade } \\
\hline & & Very good & Good & Medium & Poor & Non \\
\hline \multirow[t]{4}{*}{ Mudstone } & TOC (\%) & $>6$ & $3-6$ & $1.5-3$ & $0.75-1.5$ & $<0.75$ \\
\hline & Chloroform pitch "A"/\% & $>0.12$ & $0.06-0.12$ & $0.03-0.06$ & $0.015-0.03$ & $<0.015$ \\
\hline & $\mathrm{S}_{1}+\mathrm{S}_{2}(\mathrm{mg} / \mathrm{g})$ & $>20$ & $6-20$ & $2-6$ & $0.5-2$ & $<0.50$ \\
\hline & Total hydrocarbons $/ \times 10^{-6}$ & $>700$ & $300-700$ & $120-300$ & $50-120$ & $<50$ \\
\hline Organic matter type & & & $\mathrm{l}_{1}$ & $\mathrm{I}_{2}$ & II & $\mathrm{III}_{1}$ \\
\hline
\end{tabular}

\section{Types of Organic Matter in the Mud Shale of the Study Area}

The content levels of the seven shale sapropelic formations in the Shanxi Formation ranged from 0 to $2 \%$, with an average of $0.57 \%$. The exinite content ranged from 15 to $66 \%$, with an average of $48.57 \%$. The vitrinite content ranged from 24 to $62 \%$, with an average of $37.57 \%$. The average composition of inertinite ranged between 6 and 15\%, with an average of 10.14\%, and the Ti index type ranged from -58 to 5 , with an average of -14.69 . According to the results, the organic matter types of the Shanxi Formation were mainly type $\mathrm{III}$ and type $\mathrm{II}_{2}$.

The sapropelic content levels of 59 samples from the Taiyuan Formation were found to range from 0 to $50 \%$, with an average of $4.51 \%$. In addition, the content levels of exinite ranged between 0 and $81 \%$, with an average of $38.97 \%$. The vitrinite content levels were between 12 and $81 \%$, with the average determined to be $42.53 \%$. The inertinite content ranged from 1 to $23 \%$, with an average value of $9.76 \%$. The $\mathrm{Ti}$ index type ranged from -79 to 75 , with an average value of -13.99 . Therefore, the organic matter types of the Taiyuan Formation were mainly type III, followed by type $\mathrm{II}_{2}$.

In summary, the shale of the Shanxi and Taiyuan Formations was dominated by exinite and vitrinite. The content of exinite in the Shanxi Formation was greater than that of the vitrinite, while the content of vitrinite in the Taiyuan Formation was the opposite. It was determined that the main organic matter types of the Shanxi Formation in the study area were type III and type $\mathrm{II}_{2}$, and the main organic matter types of the Taiyuan Formation were mainly of Algebrine types. However, the marine and continental transition facies of the Shanxi and Taiyuan Formations in the Ordos Basin were both found to be suitable types for gas generation (Xue et al., 2019; Zhai et al., 2020). The results indicated that the source rock of the Taiyuan Formation in the study area had better hydrocarbon generation ability.

\section{Abundance of Organic Matter in the Mud Shale of the Study Area}

The parent material of shale gas is organic matter. The relative content of organic matter is expressed by the abundance of organic matter. Therefore, the abundance of organic matter is an important indicator for determining the hydrocarbon generation potential of shale gas. Total organic carbon content

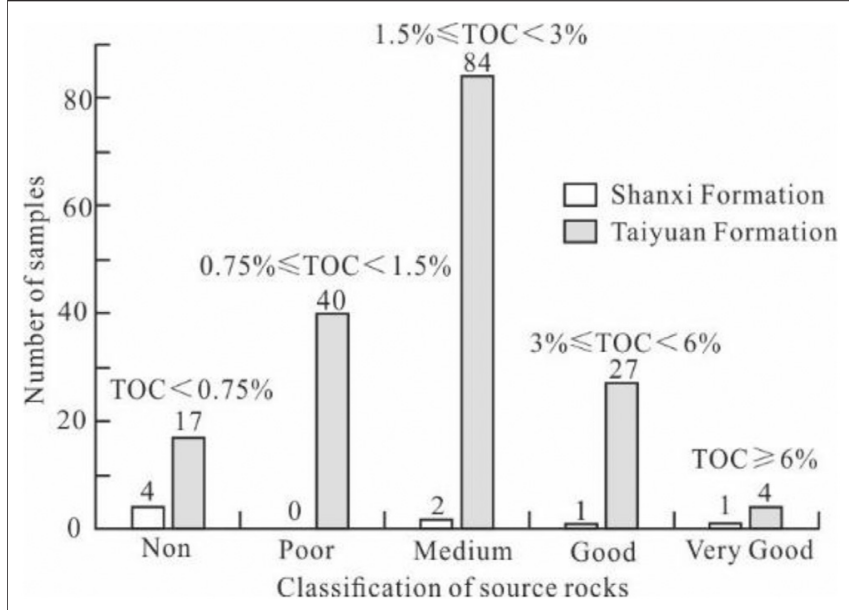

FIGURE 4 | TOC evaluation statistics for typical boreholes.

(TOC), chloroform bitumen "A," and the hydrocarbon generation potential $\left(S_{1}+S_{2}\right)$ are all common indicators which are utilized in evaluations of the abundance of organic matter in source rock (Chen et al., 1997) (Table 1). In the current study, based on the results of the measured analysis of the organic matter abundance index of the shale in the Shanxi and Taiyuan Formations of the study area, it was concluded that the source rock was mainly medium coal-measure source rock and had good hydrocarbon generation potential.

\section{Organic Carbon Content}

According to the test results of shale samples from the parameter wells in the study area and the logging inversion results of the coal exploration holes, it was considered that most of the source rocks were medium coal-measure source rocks. The results of this study's TOC content analysis of 181 samples from Wells YY1, CY1, XY601, and DY3-2 revealed that the organic carbon content levels of the Shanxi and Taiyuan Formations were slightly different. The nine samples from the Shanxi Formation showed that they were mainly nonsource rock and medium source rock (Figure 4), with TOC ranging from 0.21 to $6.26 \%$ and an average of $2.15 \%$. The overall source rock level was determined to be medium. The 172 samples obtained from the Taiyuan Formation were mainly medium source rock, followed by poor source rock, and good source rock, respectively, as shown 


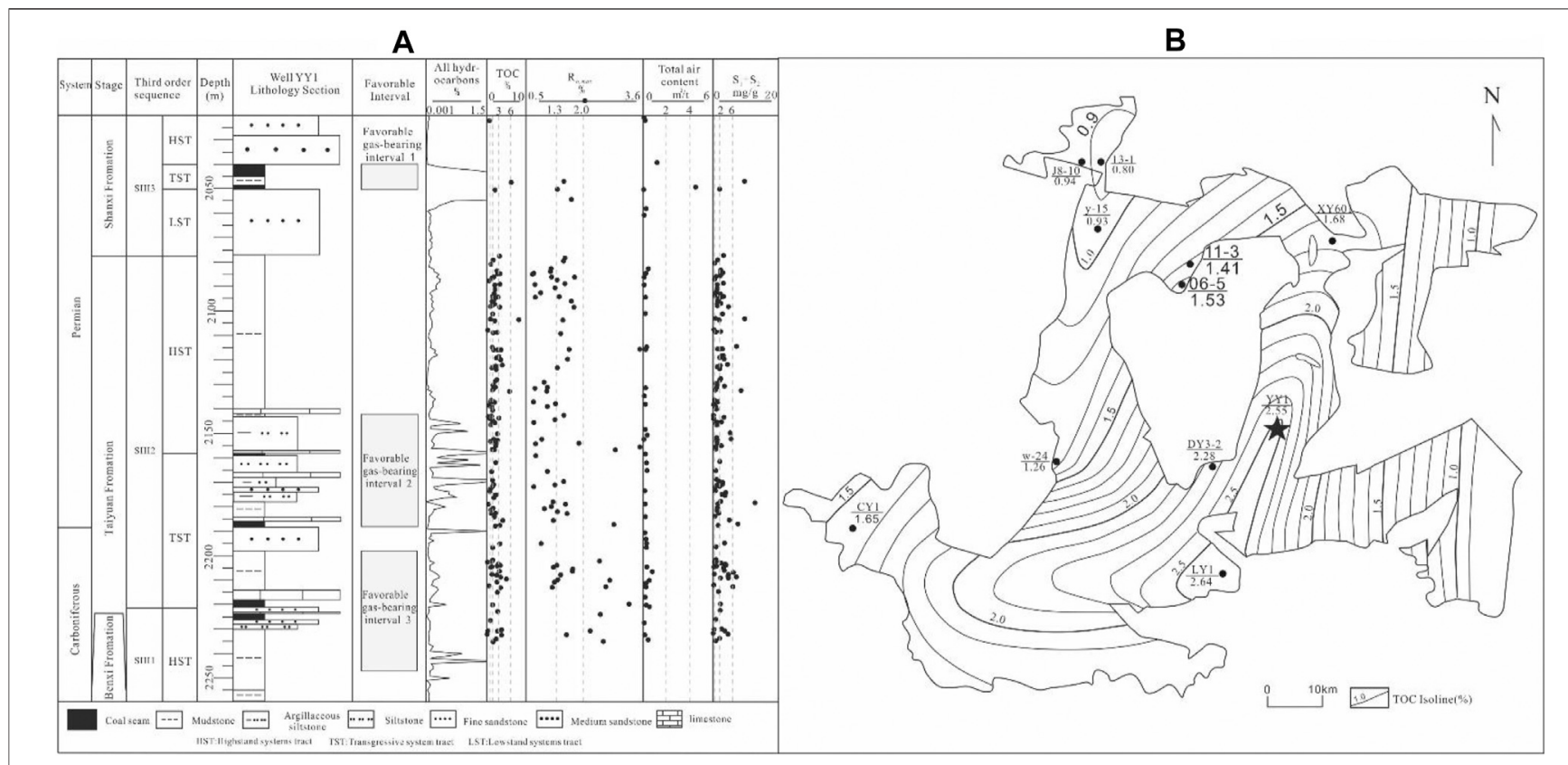

FIGURE 5 | TOC features of the Shanxi and Taiyuan Formations shale.

in Figure 4. The TOC ranged from 0.23 to $10.62 \%$, with an average of $2.15 \%$. The overall source rock level was also determined to be medium. The TOC of Well YY1 was tested 145 times. The results revealed that the TOC ranged from 0.23 to $8.11 \%$, with an average of $2.03 \%$. The high value areas with TOC $>$ of $3.0 \%$ were mainly concentrated in the middle and lower parts of the Taiyuan Formation. The YY1 area of the Taiyuan Group's sandstone and the shale depositional environment in the marina outer shelf-barrier-lagoon and tidal flat environments were given priority. This was due to the regional stability of the coal seams, dark mudstone, carbonaceous mudstone, siltstone, fine sandstone and limestone layers, and sandstone sections containing high amounts of organic matter. The Taiyuan Group sandstone and shale displayed no obvious differences in total organic carbon content, as shown in Figure 5A.

At the same time, coal exploration drilling holes in Kaihe, Liangbaosi, Wanfu, Yuncheng, and Heihumiao were selected for this study's logging inversions. The TOC content of the Shanxi Formation was found to range between 0.17 and $1.65 \%$ and that of the Taiyuan Formation ranged between 0.48 and $2.93 \%$.

In the current investigation, the above-mentioned data were combined, and it was determined that the minimum TOC value of the Shanxi Formation and Taiyuan Formation was $0.17 \%$; maximum TOC value was $10.62 \%$; and the majority ranged between 1.0 and $2.5 \%$. In addition, it was observed that when compared with the Ordos Basin, the study area of the Shanxi Formation was found to have better potential than the Ordos Basin, and the organic matter development of Taiyuan Formation was like that of the Ordos Basin (Xue et al., 2019; Kuang et al., 2020; Zhai et al., 2020). On the plains, the Yutai Sag and the first line

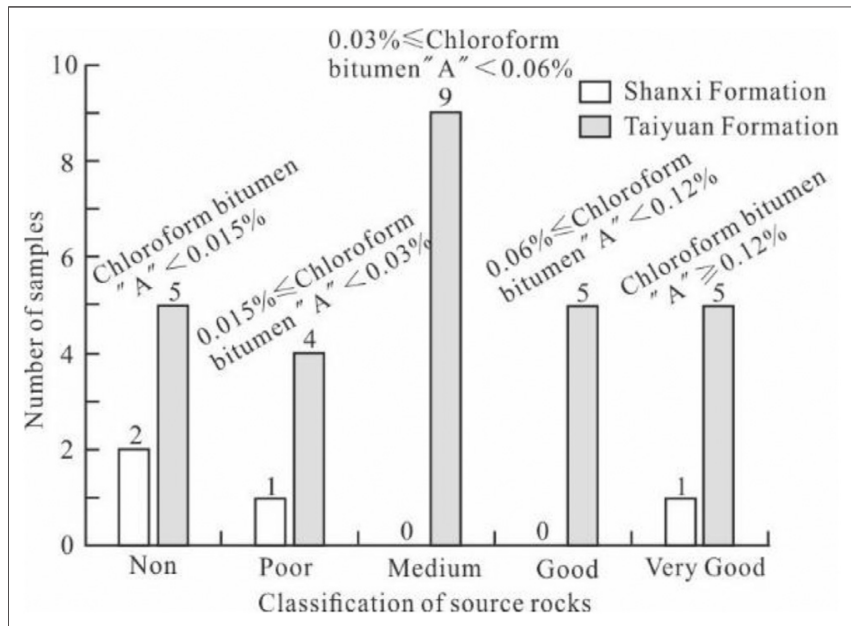

FIGURE 6 | Evaluation statistics of the chloroform bitumen "A" content in typical boreholes.

of the Shanxian coalfield displayed a distribution trend of "high in the middle and low on both sides," as detailed in Figure 5B. The abundance of organic matter was medium, which met the conditions for shale gas generation.

\section{Chloroform Bitumen "A"}

In this study, 32 samples of chloroform bitumen " $A$ " obtained from Well XY601, Well DY3-2, and Well CY1 were analyzed. It was found that the chloroform bitumen " $\mathrm{A}$ " of the four shale samples from the Shanxi Formation ranged between 0.003 and $0.14 \%$, with an average of $0.04 \%$. Those results indicated that they 

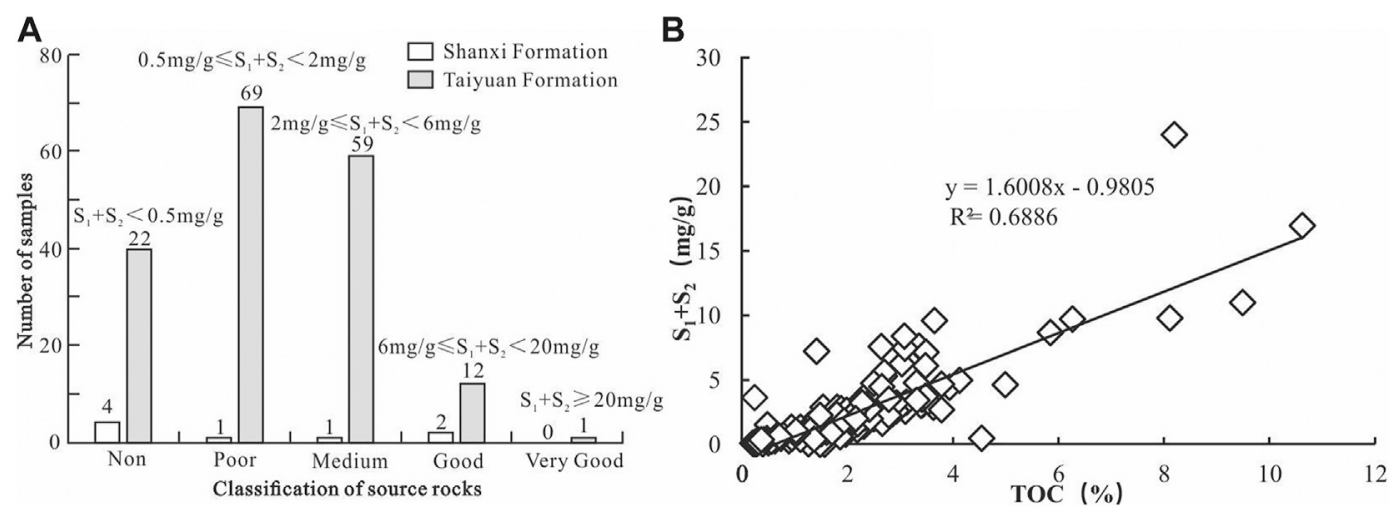

FIGURE 7 | Hydrocarbon generation potential evaluation statistics of mudshale and the relationship between them and TOC.

were medium source rock. The chloroform bitumen "A" of 28 shale samples from the Taiyuan Formation was found to range from 0.005 to $0.42 \%$, with an average value of $0.08 \%$, which indicated that the source rock is good and superior to that of the Shanxi Formation (Figure 6).

\section{Potential for Hydrocarbon Generation}

According to the analysis results of 171 pyrolysis samples from Wells YY-1, CY-1, XY601, and DY3-2 (Figure 7A), the $S_{1}+S_{2}$ content of eight shale samples from the Shanxi Formation ranged from $0.09 \mathrm{mg} / \mathrm{g}$ to $9.73 \mathrm{mg} / \mathrm{g}$, with an average of $2.63 \mathrm{mg} / \mathrm{g}$. The grade of the source rock was nonsource rock to medium source rock. The content of $S_{1}+S_{2}$ in 163 shale samples from the Taiyuan Formation ranged from $0.01 \mathrm{mg} / \mathrm{g}$ to $24.00 \mathrm{mg} / \mathrm{g}$, with an average of $2.43 \mathrm{mg} / \mathrm{g}$, and the grade of source rock was medium. The potential hydrocarbon generation capacity of the Taiyuan Formation and the Shanxi Formation was found to be slightly different. The potential hydrocarbon generation of each sample $\left(\mathrm{S}_{1}+\mathrm{S}_{2}\right)$ had a significant positive correlation with the TOC (Figure 7B). The potential hydrocarbon generation capacities of the shale of the Shanxi and Taiyuan Formations were not significantly different from that of the Ordos Basin (Xue et al., 2019), which was related to the fact that the Yanshanian volcanic activities in the study area had occurred during the accumulation period of the regional source rock, and those activities had promoted the regional hydrocarbon generation.

\section{Organic Matter Maturity}

The degrees of organic matter maturity reflect the degrees of maturity and evolution of source rock organic matter and can be used to determine whether or not organic matter has reached or exceeded the maturity range for hydrocarbon generation (Zhang et al., 2011). In the vertical direction, the maximum reflectance $\left(\mathrm{R}_{\mathrm{o}, \max }\right)$ of three shale samples from well YY1 was found to range between 1.33 and $1.70 \%$, with an average value of $1.51 \%$. In addition, the $\mathrm{R}_{\mathrm{o} \text {,max }}$ of 68 shale samples from the Taiyuan Formation ranged between 0.68 and $3.51 \%$, with an average value of $1.49 \%$. Therefore, it was determined that they were all in a stage of low maturitymaturity. There were no obvious differences observed in the organic matter maturity between the Shanxi Formation and the coal-bearing source rock of the transitional facies in the Ordos Basin. However, the Taiyuan Formation was determined to be lower than the Ordos Basin ${ }^{[4,17 \text { to } 19,21]}$, and the degree of thermal evolution increased with depth, as shown in Figure 5A. The values of the $\mathrm{R}_{\mathrm{o}, \max }$ in the Taiyuan Formation were found to be relatively large. Some sections of the study area were found to have been affected by the late Yan Mountains magmatic intrusion, which had accelerated the maturation of the source rock around the intrusive rock. In the current study, based on previous data, it was determined that the $\mathrm{R}_{\mathrm{o} \text {,max }}$ in southwestern Shandong ranged between 0.68 and $3.51 \%$, with an average of $1.51 \%$. In addition, from the $\mathrm{R}_{\mathrm{o} \text {,max }}$ contour maps of the Shanxi and Taiyuan Formations in southwestern Shandong (Figure 8), it could be seen that the $\mathrm{R}_{\mathrm{o} \text { max }}$ plane gradually increased from north to south, which was considered to be closely related to the burial depths of the shale. Most of the study area was in a lowmaturity state, with mature resources concentrated near the Chengwu Depression.

\section{CHARACTERISTICS OF SHALE GAS RESERVOIRS}

\section{Petrology Characteristics and Mineral Content Levels}

This study's X-ray diffraction analysis results of the shale in Well YY1 (twenty-nine samples) indicated that the siliceous mineral content was relatively high. The brittle minerals accounted for $18.27-84.23 \%$, with an average of $47.21 \%$, which was mainly quartz, followed by feldspar, and with small amounts of calcite, dolomite, pyrite, and clay minerals mainly mixed in the kaolinite, illite, and imonite layers. The kaolinite, imonite mixed layers, quartz, feldspar, dolomite, and Pyrite successively accounted for 5-68\%, 0-81\%, 13.96-53.91\%, $0-24.83 \%, 0-10.09 \%$, and $0-8.2 \%$, with an average of $30,27.04$, $41.25,8.19,0.90$, and $1.88 \%$ accounted for $0-81 \%$, with an average of $27.04 \%$. Quartz accounted for $0-81 \%$, with an average of $27.04 \%$. The Brittleness Index II represented the fracturing ability of the shale (Zhang et al., 2015; Brittleness Index II = (quartz + feldspar + calcite + dolomite $) /($ quartz + 


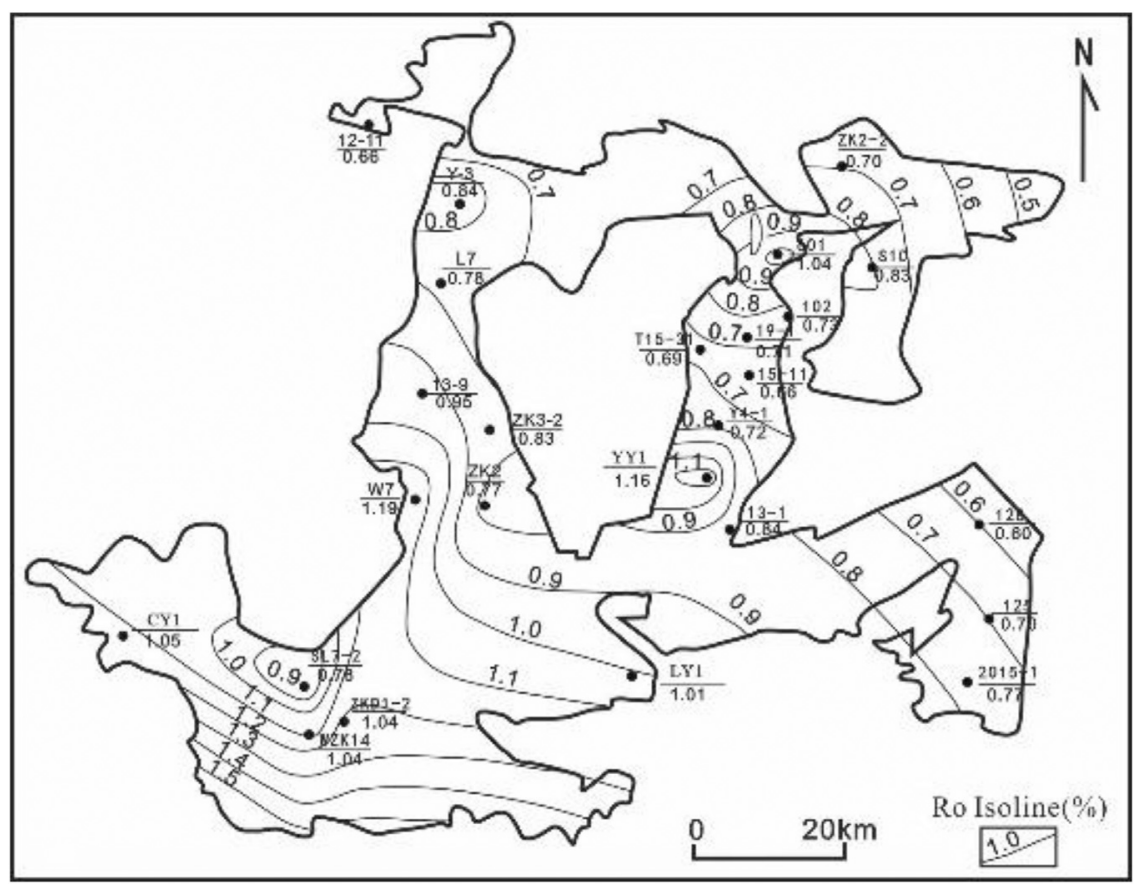

FIGURE 8 | Organic matter maturity distribution in the Shanxi and Taiyuan Formations.
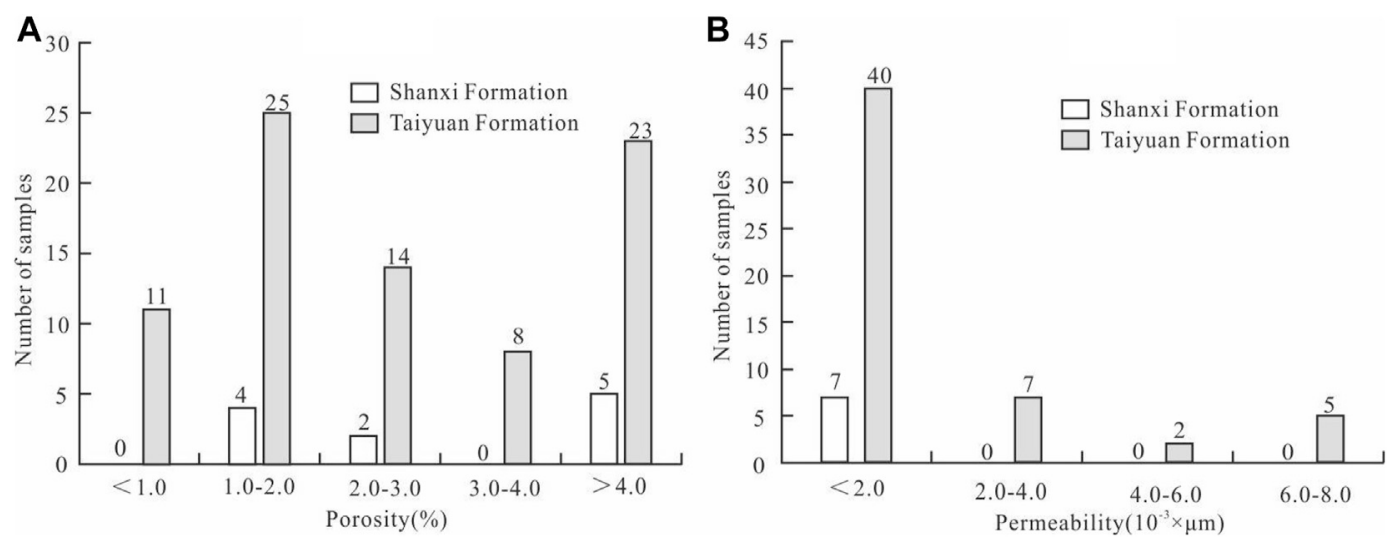

FIGURE 9 | Porosity distribution and permeability distribution of the mudshale.

feldspar + calcite + dolomite + clay minerals $) \times 100 \%)$. It was found that the Taiyuan Formation was rich in brittle minerals with a higher fraction of brittleness index (Brittleness Index II was $14.22-81.73$, with an average of 51.61 ), which was slightly better than that of the Ordos Basin (Xue et al., 2019; Kuang et al., 2020; Zhai et al., 2020). Therefore, it was considered to have conditions which would be suitable for future industrial development.

\section{Physical Characteristics of the Study Area}

Permeability levels are highly significant for determining the economic development values of shale gas reservoirs. The permeability of shale tends to be very low and increases with the development of rock fractures (Fu et al., 2018). The porosity of the shale in Shanxi Formation was determined to range from 1.0 to $9.43 \%$, with an average of $4.33 \%$ for a total of eleven samples. Also, the permeability was $0.02 \times 10^{-3}$ to $1.40 \times$ $10^{-3} \mu \mathrm{m}^{2}$, with an average of $0.22 \times 10^{-3} \mu \mathrm{m}^{2}$ for eight samples. The porosity of the shale in the Taiyuan Formation ranged between 0.33 and $11.96 \%$, with an average of $3.26 \%$ for a total of 81 samples. The permeability was determined to range from $0.01 \times 10^{-3}$ to $7.98 \times 10^{-3} \mu \mathrm{m}^{2}$, with an average of $1.36 \times$ $10^{-3} \mu \mathrm{m}^{2}$ for 54 samples. The porosity and permeability conditions of the Shanxi and Taiyuan Formations were found 


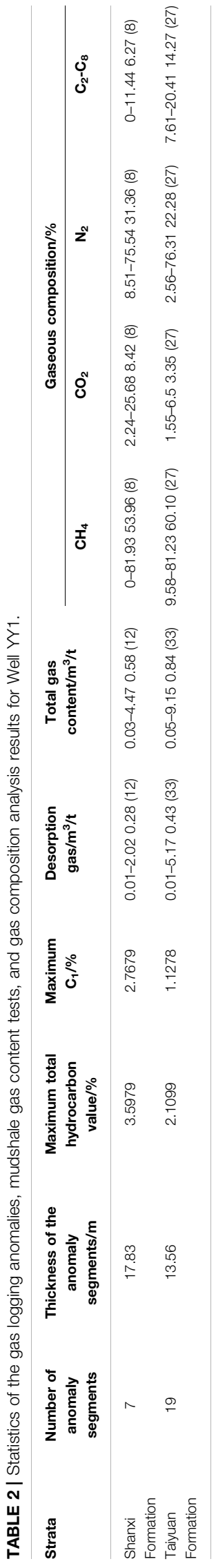

to be similar, as shown in Figures 9A,B. They were determined to belong to low porosity and low permeability reservoirs overall and were not significantly different from the Ordos Basin (Xue et al., 2019; Kuang et al., 2020; Zhai et al., 2020). These findings indicated that the shale in the study area had relatively good reservoir capacity.

\section{Gaseous Characteristics of the Study Area}

Taking Well YY1 as an example, this study determined that, based on the previous data analysis results, the gas logging processes (using the SK-2000G gas logging tool) had revealed 32 layers of gas logging anomalies at different levels in the Shanxi and Taiyuan Formations (Table 2). The cumulative thickness of the abnormal intervals was $38.84 \mathrm{~m}$, of which the Taiyuan Formation had the most gas measurement anomaly segments. However, the cumulative thickness of the anomaly segments was lower than that of the Shanxi Formation. The highest maximum total hydrocarbon value $(3.5979 \%)$ was found in the Shanxi Formation.

This study's field gas content desorption test results showed that the desorption volume of Shanxi Formation was between 0.01 and $2.02 \mathrm{~m}^{3} / \mathrm{t}$, with an average of $0.28 \mathrm{~m}^{3} / \mathrm{t}$. The total gas content ranged between 0.03 and $4.47 \mathrm{~m}^{3} / \mathrm{t}$, with an average of $0.58 \mathrm{~m}^{3} / \mathrm{t}$. The desorption volume of the Taiyuan Group ranged from 0.01 to $0.29 \mathrm{~m}^{3} / \mathrm{t}$, with an average of $0.08 \mathrm{~m}^{3} / \mathrm{t}$, and the total gas content ranged from 0.05 to $0.69 \mathrm{~m}^{3} / \mathrm{t}$, with an average of $0.22 \mathrm{~m}^{3} / \mathrm{t}$. This study's wet tests of the shale samples from the Shanxi and Taiyuan Formations showed obvious bubbles. It was observed in the ignition test of the desorption sample that the flame was light blue, could not burn smoothly in the air, and was accompanied with a boom sound. The analytical gas-gas composition analysis results (Table 2) indicated that the gas compositions of the Shanxi and Taiyuan Formations were dominated by $\mathrm{CH}_{4}$, followed by $\mathrm{N}_{2}$ and $\mathrm{CO}_{2}$ and $\mathrm{C}_{2}-\mathrm{C}_{8}$ in lower amounts. The content levels of $\mathrm{CH}_{4}$ in the Shanxi Group ranged up to $81.93 \%$, with an average of $53.96 \%$. Meanwhile, that in Taiyuan Group ranged up to $74.47 \%$, with an average of $57.77 \%$. The direct data from the gas logging and field analysis results showed that the Taiyuan and Shanxi Formations in the Jining Depression had certain hydrocarbon generation abilities and gas storage capacities. The shale gas and $\mathrm{CH}_{4}$ content levels of the Shanxi and Taiyuan Formations in the study area were found to be obviously lower than those of the Ordos Basin (Xue et al., 2019; Kuang et al., 2020; Zhai et al., 2020).

\section{Characteristics of the Shale Gas "Sweet Spots" (Points of Interest)}

The concept of sweet spots (points of interest) was first proposed by Shurr and Ridgley, (2002) and was later used in the evaluations of unconventional oil and gas resources (Pollastro, 2007). Chinese researchers have expanded the use range of sweet spots (Yang et al., 2015; Zou et al., 2015; Ma et al., 2018) to the most concentrated oil and gas enriched intervals, which are defined as "sweet-spot intervals" and serve as the target intervals for exploration and development. The Lower Shihezi Formation was excluded from the evaluation layers due to its low brittleness 


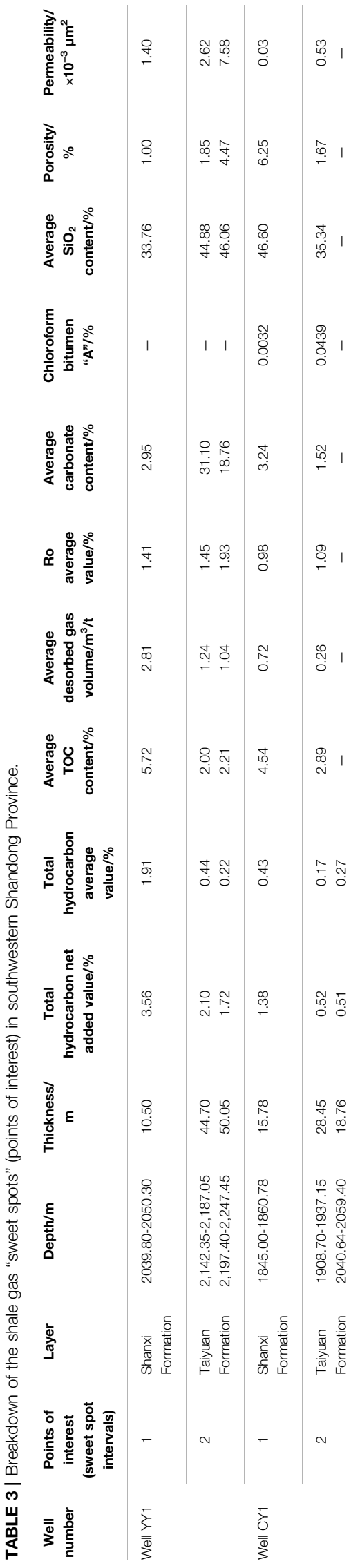

index, TOC, $S_{1}+S_{2}$, porosity, and gas content. The Xiazhihezi Formation was also excluded from the evaluation layers.

In the present research investigation, the mud shale reservoir evaluation system (Zhang et al., 2011; Fu et al., 2018; Qiu et al., 2020) was referenced and the data obtained from wells CY1, YY1, LAY1, and LY1 were comprehensively analyzed. Therefore, it was believed that the composite evaluation layers of the Shanxi and Taiyuan Formation had three developed "sweet spots," as shown in Figure 5A. This study's division basis is detailed in Table 3. For example, for the YY1 Well, the desert section was in the initial flooding surfaces, as well as in the flooding surfaces near the sea. Therefore, those areas were given priority due to the observed sea development in the transgressive system tracts and high system domain; lithology combination of coal-mudstone-silty mudstone presence of argillaceous siltstone (mainly limestone); and the sedimentary environmental conditions in the lagoon, tidal flat, peat bog, carbonate shelf, and lower delta plain areas. The specific characteristics were as follows.

\section{"Sweet Spot" Interval 1}

Interval 1 was located within the Shanxi Formation at well sections situated between 2,039.80 and $2050.30 \mathrm{~m}$. The apparent thickness was $10.50 \mathrm{~m}$, and the primary lithology was black coal and gray-black carbonaceous mudstone. The measured total hydrocarbons in the gas ranged between 0.04 and $3.60 \%$. The total hydrocarbon net value was $3.56 \%$; total hydrocarbon average value was $1.91 \%$; measured methane in the gas was between 0.03 and 2.35\%; methane net value was $2.32 \%$; methane average value was $1.24 \%$; average desorption gas volume was $2.81 \mathrm{~m}^{3} / \mathrm{t}$; TOC average value was $5.72 \%$; $\mathrm{R}_{\mathrm{o} \text {,max }}$ average value was $1.41 \%$; average $\mathrm{SiO}_{2}$ content was $33.76 \%$; carbonate content was $2.95 \%$; porosity was $1.00 \%$; and permeability was $1.40 \times 10^{-3} \mu \mathrm{m}^{2}$.

\section{"Sweet Spot" Interval 2}

The second interval with the Taiyuan Formation was located at the well sections situated between $2,142.35 \mathrm{~m}$ and $2,187.05 \mathrm{~m}$. The apparent thickness was $44.70 \mathrm{~m}$, and the primary lithology included gray-dark gray mudstone, silty mudstone, argillaceous siltstone, gray siltstone, and coal-bearing lines. The measured total hydrocarbons in the gas ranged between 0.01 and $2.11 \%$; total hydrocarbon net value was $2.10 \%$; total hydrocarbon average value was $0.44 \%$; measured methane in the gas ranged between 0.02 and $1.60 \%$; methane net value was $1.57 \%$; methane average value was $0.30 \%$; average desorbed gas volume was $1.24 \mathrm{~m}^{3} / \mathrm{t}$; TOC average value was $2.00 \%$; $\mathrm{R}_{\mathrm{o} \text {,max }}$ average value was $1.45 \%$; average $\mathrm{SiO}_{2}$ content was $44.88 \%$; carbonate content was $31.10 \%$; average porosity was $1.85 \%$; and average permeability was $2.62 \times 10^{-3} \mu \mathrm{m}^{2}$.

\section{"Sweet Spot" Interval 3}

Interval 3 was in the Taiyuan Formation at the well sections situated between $2,197.40 \mathrm{~m}$ and $2,247.45 \mathrm{~m}$. The apparent thickness was $50.05 \mathrm{~m}$, and the primary lithology included gray-dark gray mudstone intercalated with thin layers of sandstone and limestone and coal-bearing lines. The measured total hydrocarbons in the gas ranged from 0.03 to $1.75 \%$; total hydrocarbon net value was $1.72 \%$; total hydrocarbon average 


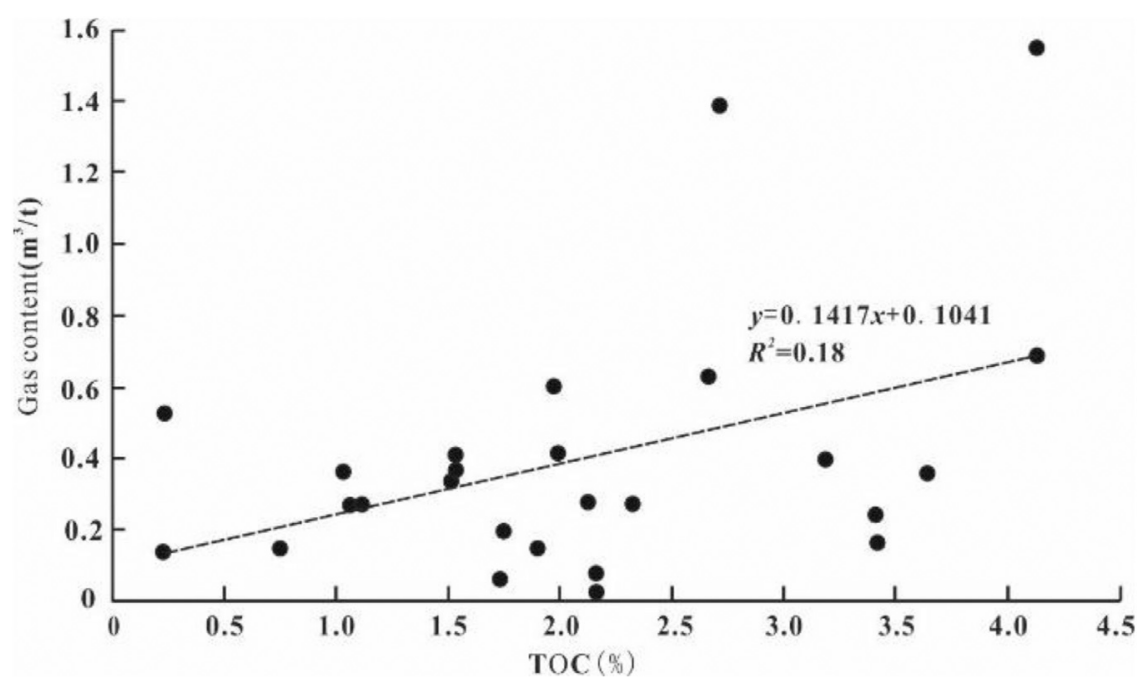

FIGURE 10 | Linear relationship model between the gas content and the TOC in the coal-bearing areas of southwestern Shandong Province.

value was $0.22 \%$; measured methane in the gas ranged between 0.01 and $1.43 \%$; methane net value was $1.42 \%$; methane average value was $0.17 \%$; average desorbed gas volume was $1.04 \mathrm{~m}^{3} / \mathrm{t}$; TOC average value was $2.21 \%$; $\mathrm{R}_{\mathrm{o} \text {, max }}$ average value was $1.93 \%$; average $\mathrm{SiO}_{2}$ content was $46.06 \%$; carbonate content was $18.76 \%$; average porosity was $4.47 \%$; and the average permeability was $7.58 \times 10^{-3} \mu \mathrm{m}^{2}$.

\section{Characteristics of the Distribution Planes}

There was observed to be little measured gas content data for the shale in the Shanxi and Taiyuan Formations area. The gas content of the organic-rich mud shale in the Shanxi and Taiyuan Formations, which had been measured from Wells YY1 and CY1, was determined to be between $0.03 \mathrm{~m}^{3} / \mathrm{t}$ and $4.47 \mathrm{~m}^{3} / \mathrm{t}$, with an average of $0.30 \mathrm{~m}^{3} / \mathrm{t}$. Since gas content is known to be positively correlated with TOC (Zou et al., 2014; Qiu et al., 2020), the gas content of the shale in the study area was estimated based on the results. Then, using the completed gas content and TOC test data from Wells CY1, YY1, LY1, along with the surrounding Well LAY1, a linear relationship model between the gas content and TOC in the southwestern Shandong area was established, as illustrated in Figure 10. Subsequently, by calculating the corresponding gas content according to the TOC values of the shale throughout the entire study area, it was determined that the Jining-Yutai Depression and the Chengwu Depression were potentially high gas-bearing areas. The potential gradually decreased to the northwest and southeast wings, with the Yutai Depression displaying the highest overall potential (above $0.5 \mathrm{~m}^{3} / \mathrm{t}$ ).

\section{PREDICTED SHALE GAS RESOURCE FORECASTS}

\section{Forecasting Standards}

This study consulted the evaluations of the shale gas resources survey sampling test results of the Tribune of Land and
Resources, as well as the "regulations of technology of shale gas resource evaluations (draft)" data from the Geological Survey Institute of Shandong Province, and the requirements for determining shale gas resources were compiled. Then, by combining the characteristics of China's shale gas, the shale gas distribution divisions were divided into vision areas and core areas which were favorable for Level 3 resources.

Recently, a breakthrough in marine-continental transitional shale gas exploration was achieved in the eastern margin of the Ordos Basin. This study found that when compared with the Ordos Basin, the shale of the Shanxi and Taiyuan Formations in the study area had displayed similar geological characteristics which could potentially indicate rich shale gas resources and major development potential. The favorable geological characteristics of the study area were as follows:

a) The sedimentary environmental conditions were stable and the sedimentary thicknesses were larger than those of the Ordos Basin. The vertical sedimentary sequence was interbedded with shale, coal seams, and densifying siltstone, and organic-rich shale was found to be distributed in a large area.

b) The main types of organic matter in the Shanxi Formation were Type III and Type Quan 2 kerogen. The main types of organic matter in the Taiyuan Formation were lacustrine types. The abundance and maturity of the organic matter were observed to be high and the gas generating capacity was strong.

c) The reservoir rock mineral composition was complex. The clay mineral content was relatively high. Also, the content of brittle minerals was rich and found to be slightly better than that of the Ordos Basin, with good shale fracturing ability observed.

d) The study area was categorized as containing low porosity and low permeability reservoirs, with relatively good reservoir capacities observed. 
TABLE 4 | Reference standards for shale gas selection in the coal-bearing areas of Shandong Province.

\begin{tabular}{|c|c|c|c|c|c|c|c|c|}
\hline $\begin{array}{l}\text { Type } \\
\text { classification }\end{array}$ & TOC/\% & Ro/\% & $\begin{array}{c}\text { Buried } \\
\text { depth/m }\end{array}$ & $\begin{array}{c}\text { Surface } \\
\text { conditions }\end{array}$ & $\begin{array}{l}\text { Preservation } \\
\text { condition }\end{array}$ & $\begin{array}{c}\text { Average } \\
\text { interval } \\
\text { gas content }\end{array}$ & $\begin{array}{l}\text { Effective } \\
\text { coverage } \\
\text { thickness }\end{array}$ & $\begin{array}{l}\text { Degree } \\
\text { of control }\end{array}$ \\
\hline $\begin{array}{l}\text { Class I Favorable } \\
\text { Area }\end{array}$ & $\begin{array}{l}\text { Average not less } \\
\text { than } 2.0 \%\end{array}$ & $\begin{array}{l}\text { Not less } \\
\text { than } 0.5 \%\end{array}$ & $300-4,500$ & Good & $\begin{array}{l}\text { Medium structure, } \\
\text { continuing strata } \\
\text { development, } \\
\text { traceable } \\
\text { correlation }\end{array}$ & $\begin{array}{l}\text { Not less than } \\
0.5 \mathrm{~m}^{3} / \mathrm{t}\end{array}$ & $\begin{array}{l}\text { Pre-Cenozoic stratum } \\
\text { thickness }>300 \mathrm{~m}\end{array}$ & $\begin{array}{l}\text { Drilling shows } \\
\text { good results }\end{array}$ \\
\hline $\begin{array}{l}\text { Class II Favorable } \\
\text { Area }\end{array}$ & $\begin{array}{l}\text { Average not less } \\
\text { than } 2.0 \%\end{array}$ & $\begin{array}{l}\text { Not less } \\
\text { than } 0.5 \%\end{array}$ & $300-4,500$ & Good & $\begin{array}{l}\text { Medium structure, } \\
\text { continuing strata } \\
\text { development, } \\
\text { traceable } \\
\text { correlation }\end{array}$ & $\begin{array}{l}\text { Not less than } \\
0.5 \mathrm{~m}^{3} / \mathrm{t}\end{array}$ & $\begin{array}{l}\text { Pre-Cenozoic stratum } \\
\text { thickness }>300 \mathrm{~m}\end{array}$ & \\
\hline Prospective Areas & $\begin{array}{l}\text { Average not less } \\
\text { than } 0.5 \%\end{array}$ & $\begin{array}{l}\text { Not less } \\
\text { than } 0.4 \%\end{array}$ & $100-4,500$ & Good & $\begin{array}{l}\text { Extant regional } \\
\text { development and } \\
\text { distribution of } \\
\text { shale } \\
\text { strata, moderate } \\
\text { preservation } \\
\text { conditions }\end{array}$ & No requirement & No requirements & \\
\hline
\end{tabular}

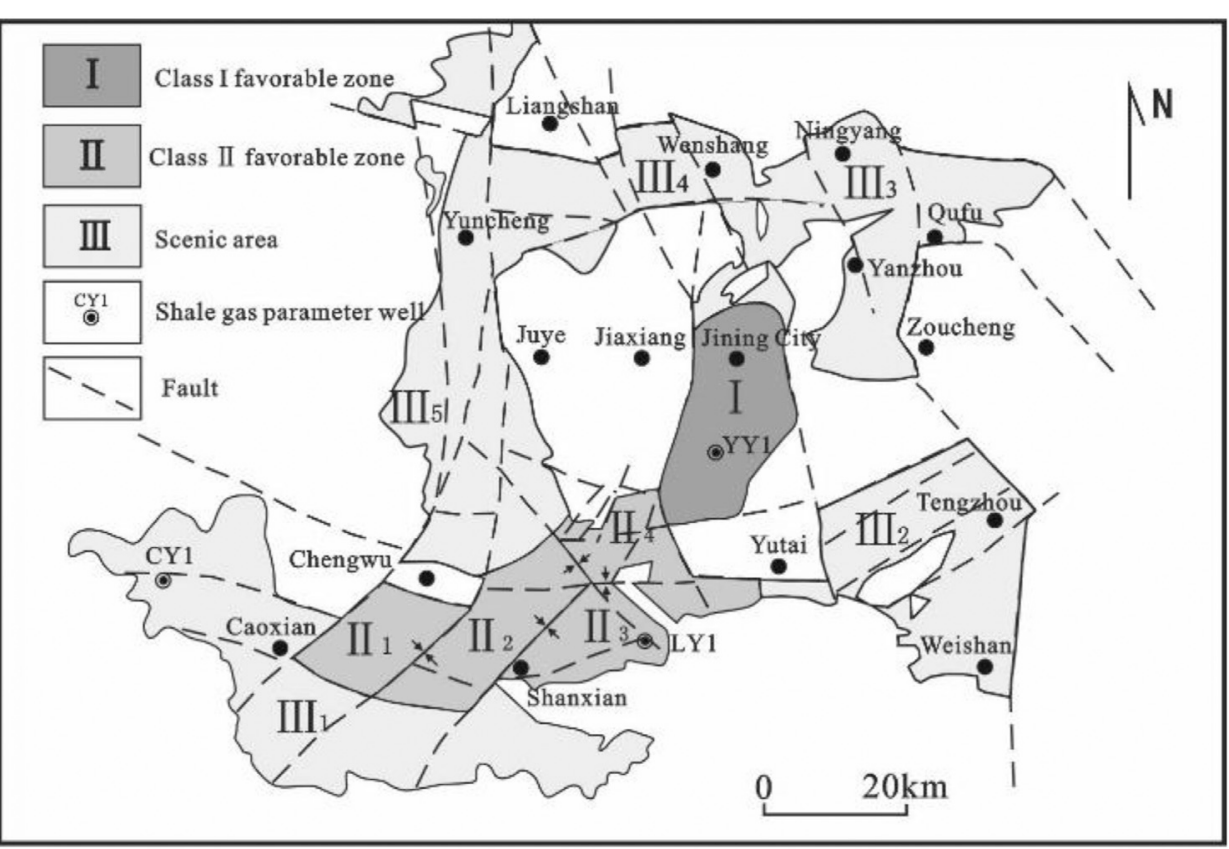

FIGURE 11 | Distribution map of the prospective and favorable shale gas areas in the western Shandong region.

e) The total gas content was general and lower than the Ordos Basin. However, the resources were rich.

f) The "sweet spot intervals" were generally located in the upper high water level system, near the initial and maximum sea flooding surfaces, and had developed in the transgressive system tract and the high-level system tract.
Although the study area was large, there are significant differences observed in the degrees of drilling, geophysical prospecting controls, and the work carried out in wells after the shale gas layers were exposed. Therefore, in order to more accurately reflect the current state of the shale gas resource explorations in the coal-bearing areas of Shandong Province, the optimal conditions for favorable shale gas areas and 
prospective areas across China were prioritized. Zhang et al. (2012b) further divided the favorable areas into Type I and Type II favorable areas according to the degrees of control in the shale gas surveys. The specific selection criteria are outlined in Table 4. In this study's survey, based on the Shanxi and Taiyuan Formation composite evaluation layers, the Class I and Class II favorable areas, as well as potential prospective areas, were identified in the study region, as detailed in Figure $\mathbf{1 1}$.

\section{Forecasting Results}

The Upper Paleozoic Carboniferous-Permian strata in southwestern Shandong Province represented a major sedimentation transgression period. The strata experienced the entire process of an epicontinental basin's formation, development, flourishing, shrinkage, and transformation. It also experienced the evolutionary process of a tidal flat-lagoon sedimentary system $\rightarrow$ platform-lagoon sedimentary system $\rightarrow$ delta sedimentary system $\rightarrow$ meandering river sedimentary system. As a result, the strata are characterized by multiple developed layers of stable integrated limestone in contact with the underlying strata, all of which being conducive to the preservation of shale gas.

During the Early and Middle Triassic Periods, due to the remote effects of plate collision, a compressional continental basin was formed in the northern margin of the West Shandong Block and fluviolacustrine detrital assemblages were deposited. Then, during the Late Triassic Period, the basin was uplifted due to the influencing effects of the reentry and uplift of the rock at the root of the orogenic belt. The sediments during the Early and Middle Triassic Period were mainly denuded, forming an important unconformable interface between the Mesozoic and Paleozoic strata. During the Jurassic Period, local subsidence occurred. The Early Cretaceous magmatic activities were extensive and intense, making it the most intense magmatic activity period in Shandong. The Cenozoic tectonic framework exhibited obvious characteristics of inheritance and neogenesis, and the tectonic characteristics and dynamic evolution inherit the Mesozoic tectonic characteristics, which form the present tectonic framework of the study area. It was observed that when compared with the surrounding area, the central part of the study area had experienced relatively weak tectonic activities and faults were not developed. The preservation conditions of shale gas in the study area were destroyed to some extent, which led to a general decrease in the total gas content of the formation. Therefore, to identify favorable blocks for shale gas in southwestern Shandong, in addition to the development of dark shale strata, it was also necessary to select areas with relatively weak tectonic activity and underdeveloped faults. Those areas were the most conducive to the preservation of the Late Paleozoic strata, which could potentially provide favorable conditions for the occurrence of shale gas.

This study collected and then integrated, sorting through the relevant geological and mineral data for southwestern Shandong, the actual conditions in western Shandong Province. Subsequently, five advantageous areas and five prospective areas were identified, including one Class I favorable area and four Class II advantageous areas. Among the identified areas, the favorable area of Category I was $819.06 \mathrm{~km}^{2}$ with $985.84 \times 108 \mathrm{~m}^{3}$ of resources; the favorable area of Category II was $1,979.68 \mathrm{~km}^{2}$ with $2,278.14 \times 108 \mathrm{~m}^{3}$ of resources; and the prospective area measured $8,385.52 \mathrm{~km}^{2}$ with $7,299.48 \times 108 \mathrm{~m}^{3}$ of resources, as detailed in Figure 11.

\section{Class I Favorable Area}

The drilling revealed good results, with points of interest mainly located within the Jining-Yutai Depression, in the southeastern section of the coal-bearing area in southwestern Shandong (Figure 11). This favorable area had relatively abundant seismic, drilling, and geochemical data. The organic-rich mud shale of the Shanxi Formation and the Taiyuan Formation displayed thicknesses of 103-110 m; effective buried depths from $300 \mathrm{~m}$ to $2,500 \mathrm{~m}$; and organic carbon content levels of generally $2.0-3.0 \%$. The colonic type (III) was observed to be the most common, and the second was the sapropel humus type $\left(\mathrm{II}_{2}\right)$. The Ro generally ranged between 0.7 and $1.3 \%$. Overall, the area could be described as a monoclinic structure inclined toward the northwest.

\section{Class II Favorable Areas}

The Class II areas were comprised of four favorable areas, including Chengwu $\left(\mathrm{II}_{1}\right)$, Chengwu-Danxian $\left(\mathrm{II}_{2}\right)$, Shanxian $\left(\mathrm{II}_{3}\right)$, and Jinxiang $\left(\mathrm{II}_{4}\right)$, as shown in Figure 11. These areas were fault-block structures with two high-angle normal faults in the north-south direction and east-west direction. The stratum remained intact, and the overall structure was that of a monoclinic structure inclined to the west or southwest. The degrees of drilling control were relatively low. The shale of the Shanxi Formation and Taiyuan Formation had thicknesses ranging between 95 and $112 \mathrm{~m}$, with effective buried depths of $300 \mathrm{~m}$ to $3,500 \mathrm{~m}$. The organic carbon content levels were generally between 1.90 and $2.65 \%$. The most common organic matter type was humus (III), with the second most common being the sapropel humus type (II2). The Ro generally ranged between 0.8 and $1.2 \%$.

\section{Other Prospective Areas (Class III)}

A total of five prospective spots were also identified in the study region, as shown in Figure 11. The Cao County $\left(\mathrm{II}_{1}\right)$ prospective area was in the Cao County coal field region situated in the southwestern section of the study area and was distributed in a strip. The Tengzhou $\left(\mathrm{II}_{2}\right)$ prospective area was in and near the Tengxian coal field in the southeastern section of the study area. The Yang-Yanzhou $\left(\mathrm{II}_{3}\right)$ prospective area was in the NingyangYanzhou coal field in the northeastern section of the study area. The Wenshang $\left(\mathrm{II}_{4}\right)$ prospective area was in Wenshang County, which was situated in the northwestern section of the coalbearing area in southwestern Shandong. The LiangshanYuncheng $\left(\mathrm{III}_{5}\right)$ prospective area was identified in the Liangshan-Yuncheng-Northern Chengwu area, located in the central west and northwest portions of the study area, along a north-south strip. 


\section{CONCLUSION}

This study found that when compared with the Ordos Basin, the shale of the Shanxi and Taiyuan Formations in the southwestern section of Shandong Province had similar geological characteristics, abundant shale gas resources, and major development potential. The sedimentary environmental conditions were stable, and the sedimentary thicknesses were larger than those of the Ordos Basin. The vertical sedimentary sequence was observed to be interbedded with shale, coal seams, and densifying siltstone, and organic-rich shale was distributed in a large area. The main types of organic matter in Shanxi Formation are Type III and Type $\mathrm{II}_{2}$ kerogen. The main types of organic matter in Taiyuan Formation were lacustrine type. The abundance and maturity of the organic matter were high and the gas generating capacity was strong. The reservoir rock mineral composition was found to be complex, with relatively high clay mineral content levels. In addition, the content of brittle minerals was rich and slightly better than that of the Ordos Basin, with good shale fracturing observed. The reservoirs of the study area belonged to low porosity and low permeability reservoirs and were characterized with relatively good reservoir capacity. The total gas content was general and lower than that of the Ordos Basin. However, the resources were determined to be rich. There are three points of interest ("sweet spot intervals") identified in the vertical direction, all of which were located in the upper high water level system near the initial flood surface and the most flood surface and developed in the transgressive system tract and highlevel system tract.

According to the basic geological characteristics of the shale strata of the Shanxi and Taiyuan Formations, combined with the selection evaluation index of the marine-continental

\section{REFERENCES}

Chen, J. P., Zhao, C. Y., and He, Z. H. (1997). Criteria for Evaluating the Hydrocarbon Generating Potential of Organic Matter in Coal Measures. Pet. Exploration Development. 24 (1), 1-5. (in Chinese with English Abstract)

Chen, S. Y. (2000). Sequence Stratigraphy and Coal Accumulation Regularity of Late Paleozoic in North China. Beijing: Petroleum Industry Press. (in Chinese with English Abstract).

Fu, X. H., Zhang, M., Zhang, Q. H., Zhu, Y. M., and Guo, Y. H. (2018). Evaluation Index System for the Permo-Carboniferous Mud Shale Reservoirs of Coal Measures in Shanxi Province. J. China Coal Soc. 43 (6), 1644-1660. (in Chinese with English Abstract). doi:10.13225/j.cnki.jccs.2018.4029

Gong, G., Zhang, C. C., Gao, B. Y., Peng, W. Q., Huang, X. L., Zhang, H., et al. (2018). Study on Reservoir-Forming Conditions of Shale Gas in the Upper Paleozoic in the West of Shandong Province. China Coal Geology 30 (10), 34-38. (in Chinese with English Abstract).

Han, Z. Z., Li, Y., Gao, L. H., Qin, Z., Meng, Y., Han, M., et al. (2015). Shale Gas Potential of Carboniferous - Permian Taiyuan Formation in Western Shandon. J. Shandong Univ. Sci. Technology (Natural Sci. Edition). 34 (2), 51-57. (in Chinese with English Abstract). doi:10.3969/j.issn.1672-3767.2015.02.009

Huang, X. L. (2018). Shale Gas Exploration prospect of Shanxi and Taiyuan Formations in Coal-Bearing Area, Southwest Shandong Province. Coal Technology 37 (8), 82-85. (in Chinese with English Abstract).

Kuang, L. C., Dong, D. Z., He, W. Y., Wen, S. M., Sun, S. S., Li, S. X., et al. (2020). Geological Characteristics and Exploration and Development Prospects of Marine and Continental Transitional Shale Gas in the Eastern Marginal of transitional shale gas, Class I favorable areas and favorable areas of stratum and potential prospecting were identified in the southwestern area of Shandong. The favorable areas of Class I stratum covered an area of $819.06 \mathrm{~km}^{2}$, with a resource amount of $985.84 \times 108 \mathrm{~m}^{3}$. The favorable areas of the Dahe type covered an area of $1,979.68 \mathrm{~km}^{2}$. The resource amount was $2,278.14 \times 108 \mathrm{~m}^{3}$; the prospect area was $8,385.52 \mathrm{~km}^{2}$; the resource amount was $7,299.48 \times 108 \mathrm{~m}^{3}$, and the exploration potential was very high.

\section{DATA AVAILABILITY STATEMENT}

The original contributions presented in the study are included in the article/supplementary materials, further inquiries can be directed to the corresponding author

\section{AUTHOR CONTRIBUTIONS}

All authors listed have made a substantial, direct, and intellectual contribution to the work and approved it for publication.

\section{FUNDING}

This study is supported by the special fund project of geological exploration in Shandong Province "Exploration Prospect of Shale Gas from Shanxi Formation to Taiyuan Formation in CoalBearing Area of Southwestern Shandong Province of Eastern China." We thank our scientific research team for their help and guidance in the field investigation.

Ordos Basin. Pet. Exploration Development. 47 (03), 435-446. (in Chinese with English Abstract. doi:10.11698/PED.2020.03.01

Li, C. F. (2020a). Shale Gas Resource Potential Analysis of Carboniferous-Permian Coal Measures in Southwestern Shandong Province. Coal Geology China 32 (10), 15-21. (in Chinese with English Abstract). doi:10.3969/j.issn.16741803.2020.10.04

Li, C. F. (2020b). Unconventional Hydrocarbon Potential of Carboniferous Permian in Jining Sag. Coal Technology 39 (08), 63-66. (in Chinese with English Abstract). doi:10.13301/j.cnki.ct.2020.08.018

Lv, D., Li, Z., Wang, D., Li, Y., Liu, H., Liu, Y., et al. (2019). Sedimentary Model of Coal and Shale in the Paleogene Lijiaya Formation of the Huangxian Basin: Insight from Petrological and Geochemical Characteristics of Coal and Shale. Energy Fuels 33 (11), 10442-10456. doi:10.1021/acs.energyfuels.9b01299

Lv, D., Song, Y., Shi, L., Wang, Z., Cong, P., Van Loon, A. J., et al. (2020). The Complex Transgression and Regression History of the Northern Margin of the Palaeogene Tarim Sea (NW China), and Implications for Potential Hydrocarbon Occurrences. Mar. Pet. Geology 112, 104041. doi:10.1016/ j.marpetgeo.2019.104041

Ma, Y. S., Cai, X. Y., and Zhao, P. R. (2018). Theoretical Understanding and Practice of Shale Gas Exploration and Development in China. Pet. Exploration Development. 45 (4), 1-14. (in Chinese with English Abstract). doi:10.1016/ s1876-3804(18)30065-x

Pollastro, R. M. (2007). Total Petroleum System Assessment of Undiscovered Resources in the Giant Barnett Shale Continuous (Unconventional) Gas Accumulation, Fort Worth Basin, Texas. Bulletin. 91, 551-578. doi:10.1306/ 06200606007

Qiu, Z., Zou, C. N., Wang, H. Y., Dong, D. Z., Lu, B., Chen, Z. H., et al. (2020) Discussion on Characteristics and Controlling Factors of Differential 
Enrichment of Wufeng-Longmaxi Formations Shale Gas in South China. Nat. Gas Geosci. 31 (2), 163-175. (in Chinese with English Abstract). doi:10.11764/ j.issn.1672-1926.2019.11.003

Shurr, G. W., and Ridgley, J. L. (2002). Unconventional Shallow Biogenic Gas System. AAPG Bull. 86 (11), 1939-1969. doi:10.1306/61EEDDC8-173E-11D7$8645000102 \mathrm{C} 1865 \mathrm{D}$

Wang, L. J. (2016). Characteristics of Upper Paleozoic Mud Shale and Prediction of Shale Gas Prospects in Luxi Area, Shandong Province. Shandong Land Resour. 32 (1), 21-25. (in Chinese with English Abstract). doi:10.3969/j.issn.1672-6979.2016.01.004

Xue, C. Q., Wu, J. G., Zhong, J. H., Zhang, S. L., Zhang, B., Hao, B., et al. (2019). Study on the Development Characteristics of marine-continental Sedimentary Shales - - Taking Taiyuan Formation in Linxing Area of Ordos Basin as an Example. J. China Univ. Mining Technol. 48 (04), 870-881. (in Chinese with English Abstract). doi:10.13247/j.cnki.jcumt.000974

Yang, Z., Hou, L. H., Tao, S. Z., Cui, J. W., Wu, S. T., Lin, S. H., et al. (2015). Formation Conditions and "Sweet Spot" Evaluation of Tight Oil and Shale Oil. Pet. Exploration Development. 42 (5), 555-565. (in Chinese with English Abstract). doi:10.13247/j.cnki.jcumt.000974

Zhai, G. Y., Wang, Y. F., Liu, G. H., Zhou, Z., Zhang, C., and Liu, X. C. (2020). Enrichment and Accumulation Characteristics and Prospect Analysis of the Permian Marine Conticental Multiphase Shale Gas in China. Sediment. Geology. Tethyan Geology 40 (03), 102-117. (in Chinese with English Abstract). doi:10.19826/j.cnki.1009-3850.2020.07003

Zhang, C. C., Peng, W. Q., Gao, B. Y., Yu, D. M., and Yang, C. J. (2019). Favorable Exploration Strata and Resource Evaluation of Shale Gas in Shandong Province. Pet. Geology. Recovery Efficiency. 26 (2), 7-13. (in Chinese with English Abstract). doi:10.13673/j.cnki.cn37-1359/te.2019.02.002

Zhang, J. C., Jin, Z. J., and Yuan, M. S. (2004). Formation Mechanism and Distribution of Shale Gas Reservoirs. Nat. Gas Industry. 24 (7), 15-18. (in Chinese with English Abstract). doi:10.3321/j.issn:1000-0976.2004.07.005

Zhang, M. Y., Li, X. Q., Dong, Z. L., Guo, M., Sun, M. M., and Fan, J. P. (2015). Analyses on Mineral Compositions and Brittleness of the Lower Cambrian Hetang Formation Shale in South Anhui Province. J. Mineralogy, Petrology Geochem. 34 (1), 177-183. (in Chinese with English Abstract). doi:10.3969/ j.issn.1007-2802.2015.01.020

Zhang, W. D., Guo, M., and Jiang, Z. X. (2011). Parameters and Method for Shale Gas Reservoir Evaluation. Nat. Gas Geosci. 22 (6), 1093-1099. (in Chinese with English Abstract).

Zhang, D. W., Li, Y. X., Zhang, J. C., Qiao, D. W., Jiang, W. L., Zhang, J. F., et al. (2012a). Shale Gas Resource Potential Investigation and Evaluation in China. Beijing: Geological Publishing House. (in Chinese with English Abstract).
Zhang, Z. Q., Tian, J. X., Zhang, C. C., Cheng, G. S., Sun, W. Q., Sun, B., et al. (2012b). Shale Gas Research Progress at Home and Abroad and Shale Gas Resource Potential in Shandong Province. Shandong Land Resour. 28 (10), 1-6. (in Chinese with English Abstract).

Zhang, Z. Q., Zhang, C. J., Wang, S. J., Liu, S. C., Wang, L. M., Du, S. X., et al. (2014). Views on Classification and Contrast of Tectonic Units in Strata in Shandong Province. Shandong Land Resour. 30 (03), 1-23. (in Chinese with English Abstract). doi:10.3969/j.issn.16726979.2014.03.001

Zou, C. N., Dong, D. Z., Wang, S. J., Li, J. Z., Li, X. J., Wang, Y. M., et al. (2010). Formation Mechanism, Geological Characteristics and Resource Potential of Shale Gas in China. Pet. Exploration Development. 37 (6), 6-18. ( in Chinese with English Abstract). doi:10.1016/s1876-3804(11)60001-3

Zou, C. N., Dong, D. Z., Wang, Y. M., Li, X. J., Huang, J. L., Wang, S. F., et al. (2015). Shale Gas in China: Characteristics, Challenges and Prospects (I). Pet. Exploration Development. 42 (6), 689-701. (in Chinese with English Abstract). doi:10.1016/s1876-3804(15)30072-0

Zou, C. N., Tao, S. Z., Hou, L. H., Zhu, R. K., Yuan, L. X., Zhang, G. S., et al. (2014). Unconventional Petroleum Geology. Beijing: Geological Publishing House. (in Chinese with English Abstract).

Zou, C. N., Zhao, Q., Cong, L. Z., Wang, H. Y., Shi, Z. S., Wu, J., et al. (2021). Progress, Potential and prospect of Shale Gas Development in China. Nat. Gas Industry. 41 (01), 1-14. (in Chinese with English Abstract)

Conflict of Interest: The authors declare that the research was conducted in the absence of any commercial or financial relationships that could be construed as a potential conflict of interest.

Publisher's Note: All claims expressed in this article are solely those of the authors and do not necessarily represent those of their affiliated organizations, or those of the publisher, the editors and the reviewers. Any product that may be evaluated in this article, or claim that may be made by its manufacturer, is not guaranteed or endorsed by the publisher.

Copyright (c) 2021 Cuifang, Xinglong, Yubao and Fengke. This is an open-access article distributed under the terms of the Creative Commons Attribution License (CC $B Y)$. The use, distribution or reproduction in other forums is permitted, provided the original author(s) and the copyright owner(s) are credited and that the original publication in this journal is cited, in accordance with accepted academic practice. No use, distribution or reproduction is permitted which does not comply with these terms. 